\title{
Antecedents of effective decision making: a cognitive approach
}

Citation for published version (APA):

van Riel, A. C. R., Ouwersloot, J., \& Lemmink, J. G. A. M. (2003). Antecedents of effective decision making: a cognitive approach. METEOR, Maastricht University School of Business and Economics. METEOR Research Memorandum No. 026 https://doi.org/10.26481/umamet.2003026

Document status and date:

Published: 01/01/2003

DOI:

10.26481/umamet.2003026

Document Version:

Publisher's PDF, also known as Version of record

\section{Please check the document version of this publication:}

- A submitted manuscript is the version of the article upon submission and before peer-review. There can be important differences between the submitted version and the official published version of record.

People interested in the research are advised to contact the author for the final version of the publication, or visit the DOI to the publisher's website.

- The final author version and the galley proof are versions of the publication after peer review.

- The final published version features the final layout of the paper including the volume, issue and page numbers.

Link to publication

\footnotetext{
General rights rights.

- You may freely distribute the URL identifying the publication in the public portal. please follow below link for the End User Agreement:

www.umlib.nl/taverne-license

Take down policy

If you believe that this document breaches copyright please contact us at:

repository@maastrichtuniversity.nl

providing details and we will investigate your claim.
}

Copyright and moral rights for the publications made accessible in the public portal are retained by the authors and/or other copyright owners and it is a condition of accessing publications that users recognise and abide by the legal requirements associated with these

- Users may download and print one copy of any publication from the public portal for the purpose of private study or research.

- You may not further distribute the material or use it for any profit-making activity or commercial gain

If the publication is distributed under the terms of Article $25 \mathrm{fa}$ of the Dutch Copyright Act, indicated by the "Taverne" license above, 


\title{
Antecedents of Effective Decision Making: A Cognitive Approach $^{1}$
}

\author{
Allard C.R. van Riel ${ }^{2}$ \\ Hans Ouwersloot \\ Jos Lemmink \\ Faculty of Economics and Business Administration, \\ Maastricht University, \\ The Netherlands
}

The authors wish to acknowledge the valuable comments and suggestions for improvements from the editor, three anonymous reviewers, various colleagues, and Prof. Janjaap Semeijn from the Open University of the Netherlands.

\footnotetext{
${ }^{1}$ This article is partially based on Chapter 2, "Effectiveness and Scope of Decision Making Styles", in Van Riel, Allard C.R (2003), Effective Decision Making in the High Tech Service Innovation Process, Doctoral Dissertation, Maastricht University, Maastricht, Datawyse/Maastricht University Press.

${ }^{2}$ Corresponding author. Maastricht University, Faculty of Economics and Business Administration, Department of Marketing, P.O. box 616, 6200 MD Maastricht, The Netherlands. Phone: +31 433883778 Fax: +31 433884918 E-mail a.vanriel@mw.unimaas.nl
} 


\section{Short Biographies}

Allard C.R. van Riel is an assistant professor of logistics in the department of marketing at Maastricht University. He holds a degree in Philosophy from the University of Amsterdam and has been professionally active in educational publishing for almost ten years. His $\mathrm{PhD}$ research focused on decision-making in the high tech service innovation process (2003). He published articles on services management and marketing in the Journal of Service Research, The International Journal of Service Industry Management, The Journal of Services Marketing and The International Journal of Internet Marketing and Advertising and contributed chapters to several edited books. He can be reached at: Faculty of Economics and Business Administration, Maastricht University, P.O. Box 616, 6200 MD Maastricht, The Netherlands. Phone: +31 43 3883778 Email: a.vanriel@mw.unimaas.nl

Hans Ouwersloot is an associate professor in the department of marketing at Maastricht University. He holds a degree in Economics and a $\mathrm{PhD}$ from the Free University of Amsterdam. He can be reached at: Faculty of Economics and Business Administration, Maastricht University, P.O. Box 616, 6200 MD Maastricht, The Netherlands. Phone: +31 433883813 Email: h.ouwersloot@mw.unimaas.nl

Jos Lemmink is a professor and chairman of the department of marketing at Maastricht University. He holds a degree in Business Administration from the University of Groningen and a $\mathrm{PhD}$ from the University of Limburg. He was a market researcher for the Dutch Postal Services and Telecommunications for four years and a visiting professor at the University of Southern Queensland (Australia). He published extensively on quality management and modeling. His research interests concern service management and marketing, analyses of service processes, and marketing and the new media. He can be reached at: Faculty of Economics and Business Administration, Maastricht University, P.O. Box 616, 6200 MD Maastricht, The Netherlands. Phone: +31 433883839 Email: j.lemmink@mw.unimaas.nl 


\title{
Antecedents of Effective Decision Making: A Cognitive Approach
}

\begin{abstract}
Decision-making effectiveness has been associated with how well managers adapt their cognitive style to task requirements. In this paper, theories regarding decision-making under uncertainty and the use of judgment and intuition are reviewed and integrated. Cognitive Continuum Theory (CCT), positing a one-dimensional continuum of cognitive styles anchored by intuition and analysis, is extended: Four fundamental decision styles are identified and evaluated for their relative effectiveness under various task conditions. Propositions are developed with respect to the relationships between decision task characteristics and the likelihood of using two cognitive systems, and with respect to potential moderators of decisionmaking effectiveness. The propositions are integrated into a comprehensive theoretical model. Major contributions of the study are a conceptual clarification of the distinctions between intuition, heuristics and bounded rationality on the one hand, and the assessment of the scope of various cognitive styles as well as the identification of moderators of their effectiveness on the other. Research implications and some suggestions for managerial practice are provided.
\end{abstract}

Descriptors: decision-making, uncertainty, intuition, cognitive continuum theory, sensemaking 


\section{Daß alle unsere Erkenntnis mit der Erfahrung anfange, daran ist gar kein}

\section{Zweifel. (Immanuel Kant, Kritik der Reinen Vernunft, p.27)}

\section{Introduction}

The performance of business processes is considered to be positively and strongly correlated with the effectiveness of associated managerial decision-making (Galbraith 1973; Galbraith 1974; March 1999; Penrose 1995). Currently, rapid technological change, turbulence, and great uncertainty in most organizations' micro- and macro-environments create increasingly challenging working conditions for decision-makers. Decisions must often be made under considerable time pressure (Payne et al. 1990; Simon 1997), and in highly complex and ambiguous situations (Weick 2001), where either a lack or an affluence of information prevails and great uncertainty exists about future states of the world. Still, managers and other professional decision-makers are not supposed to simply throw dice or postpone decisions indefinitely (Bazerman 2001; Hammond 1996). They must respond fast and appropriately to what knowledge is available to them at a certain point in time (Wagner and Sternberg 1986), making intelligent use of information and experience on the one hand, and of their cognitive skills on the other (Hammond 1996; Simon 1997).

Previous research suggests that decision-makers principally deal with the aforementioned difficulties by adjusting their decision style to the requirements of the task (e.g. Agor 1986; Behling and Eckel 1991; Burke and Miller 1999; Harper 1988). Various decision styles have been identified in past research (Payne 1982; Payne 1976; Simon 1997), but little is theoretically known about the scope of particular styles, i.e. the range of situations where a style can be applied validly, or about the inherent effectiveness of particular decision styles under varying circumstances. Research is therefore urgently needed to investigate the following issue: 
Which relationships exist between various characteristics of a decision task, the use of particular decision styles, and the resulting decision-making effectiveness?

Three interrelated research questions have been formulated, in order to deal with the issue:

1. Which fundamental cognitive processes underlie decision-making, and how is their relative use articulated in various managerial decision styles?

2. How do various characteristics of the decision task influence a decision-maker's propensity to use a particular decision style?

3. Under which conditions do particular decision styles lead to effective decision-making?

The remaining part of the paper is structured as follows. First, a preliminary theoretical framework is developed for the study. By means of a review of literature from different disciplines and fields, four fundamental decision styles, based on combinations of two cognitive modes are then identified. Propositions are formulated, with respect to the likelihood of decision-makers to use a particular style under specific conditions, and then with respect to the suitability of using fundamental cognitive processes under various task conditions. The resulting propositions are integrated in a comprehensive model and the paper will be concluded with theoretical and managerial implications and several suggestions for further research.

\section{Core Concepts}

Contemporary decision tasks are challenging. Decision situations are often characterized by an absence of crucial information, information overload, the absence of structure and great complexity. The skill with which managers succeed in dealing with these conditions will largely determine how well they maintain control over business processes. Since many managers work under significant time pressure, how well they can deal effectively with the challenges will substantially affect the competitive performance of the process they control. Effective decision- 
making, characteristics of the decision task, and decision styles are core constructs in the following argument. First, working definitions of these concepts will be proposed.

\section{Effective Decision Making}

The performance objectives of a business process, such as the precise relationships between input (human and financial resources) and output, are generally determined by matters external to that process. However, independent of what the precise objectives are, process performance i.e. the extent to which managers in charge achieve or exceed the objectives - will be positively and strongly related to the effectiveness with which these managers make decisions. We define effective decision-making in such a way that, ceteris paribus, more effective decision-making in a probabilistic way leads to improved process performance. In the following, decision-making effectiveness is thus conceptualized as:

the stochastic probability that a decision relating to the management of a process contributes positively to the performance of that process.

\section{Knowledge, Information and Effective Decision Making}

Decision-making is often defined as an act of information processing: the transformation of knowledge and information into managerial action (Galbraith 1974; March 1991; Weick 1979). The concept of a mental image of the decision problem helps to understand the relationship between effective decision-making on the one hand and the need for knowledge and information on the other. Decision-makers must have a reasonably accurate and complete mental image of a business process and its interfaces with the world, in order to be able to make decisions effectively, and exert control over the process. Managers will therefore attempt to improve their understanding of the situation by making use of external information and their experience, to make more effective decisions. The resulting improvements in the quality, scope 
and detail of the mental image of the decision problem can be understood as increases in the utility of the knowledge a decision-maker possesses for executing decision tasks in the process, and thus as antecedents of more effective decision-making. The utility of knowledge is always and necessarily contextual, i.e. relative to the decision problem.

The decision-making utility of knowledge is a state of a decision-maker, varying in level between two (theoretical) extremes. At one (purely theoretical) extreme we find a total absence of useful knowledge (useful for solving a specific decision problem), and at the other extreme, the (purely theoretical) possession of all potentially useful knowledge (useful for solving a specific decision problem).

When decision-makers possess knowledge that is not useful for solving a decision problem, the probability that their decisions lead to increased process performance is based on pure chance. All other things equal, the greater the utility of the knowledge that decision-makers possess, the greater the probability that their decisions lead to increased control and improved process performance. Obviously, knowledge in itself is not a simple cumulative stock variable. The 'utility' of knowledge, or its usefulness for solving a specific decision task, can be seen as such a variable.

\section{The Decision Task}

Decision tasks vary in many respects. We define the characteristics of the decision-task as:

aspects of the decision problem that can be distinguished, and through their variation affect the needs for various decision-making resources and approaches. 


\section{Decision Styles}

It has been argued that managers can adapt their decision style so that optimal use is made of information and experience, given particular task characteristics. Adapting their decision style managers intend to increase decision-making effectiveness (Brunswik 1952; Hammond et al. 1987; Meehl 1996; Payne et al. 1990; Payne et al. 1988). In the following, the decision style is conceptualized as:

the use of a particular blend of cognitive processes in order to transform information and experience into a course of action.

In the following paragraphs, the theoretical relationships between characteristics of the decision task, decision style and decision-making effectiveness will be investigated.

\section{Underlying Use of Cognitive Systems: Four Fundamental Decision Styles}

Several managerial decision styles have been distinguished in the literature (Sauter 1999). Based upon Barnard's (1938) distinction between logical and non-logical decision processes, Herbert Simon first distinguished two formally different ways of decision-making: a rational analytical and an intuitive style (Simon 1997; Simon 1987; Simon 1957). He related the first to the rational use of information and explicit reasoning, and the latter to the use of expertise and experience.

Western epistemology, the theory of knowledge, has almost exclusively focused on explicit, rational analytical cognition and reasoning, inspired by Aristotle's works on logic, and culminating in Descartes' glorification of human reason and rational science ${ }^{\mathrm{ii}}$. Rational cognition is aimed at a symbolical representation of an objectively - or at least intersubjectively - knowable reality. For centuries, intuitive cognition - generally considered a more obscure, 
primitive, subjective or even private form of intelligence, could not compete with the objectively valid and universally reproducible truths of rational cognition. In the twentieth century, however, and largely as a result of the work of Egon Brunswik and Paul Meehl in cognitive psychology (Brunswik 1952; Meehl 1996), Herbert Simon in management theory (Simon 1997; Simon 1987) and Kenneth Hammond (Hammond and Brehmer 1973; Hammond et al. 1987) in the social sciences, the phenomenon of intuitive intelligence has regained serious academic and practical interest (Agor 1984; Isaack 1978; Taggart and Robey 1981). Intuition was no longer universally seen as simply an inferior and more primitive form of cognition, but has actually been endowed with the potential of improving on, and supplementing, rational cognition, under circumstances that impede rational cognition and explicit reasoning, such as they occur for instance in strategic decision-making (Burke and Miller 1999; Eisenhardt and Tabrizi 1995; Khatri and $\mathrm{Ng}$ 2000). Evidence for the usefulness of intuitive cognition has, however, been largely anecdotal and there is a need for theoretical foundations for this potential.

In psychology, the observation of two categorically different forms of cognitive activities has led scientists to posit the co-existence of two separate, but interactive, information-processing systems in the human brain, a rational and an experiential system (Denes-Raj and Epstein 1994; Epstein 1998; Epstein 1994; Epstein et al. 1992; Myers 2002). The two complementary systems appear to be used in parallel, whereas the relative extent to which each system is used could be said to reflect the cognitive style (Epstein 1998). Individual preferences for using one system over another have been viewed and subsequently investigated as a personality trait (BriggsMyers and McCaulley 1985; Jung 1971). Indications were found that the two cognitive systems are actually located in physically different parts of the human brain (Bechara et al. 1997), albeit not in the traditionally suggested left and right hemispheres (Simon 1987). The rational or analytical information processing system has been associated with articulate, symbolic, and explicit cause-and-effect reasoning. In contrast, the experiential system was associated with 
tacit, implicit, synthetic and, more recently, with associationist (connectionist) cognitive activities. The idea that human cognition is at least partially based on associationist or connectionist processes gained in status after the discovery of the workings of neurons and neural networks (Churchland 1995; Dutta 1993). Some fundamental characteristics of the two cognitive systems are contrasted in Table 1.

Please Insert Table 1 About Here

The observation that in actual practice hybrid styles - combinations of rational and intuitive processing - are often used by managers, has then led to the development of Cognitive Continuum Theory (Hammond and Brehmer 1973), contending that decision styles can be positioned on a continuous scale anchored at one extreme in entirely rational cognition, and at the other extreme in purely intuitive cognition. Between the two extremes, different degrees of semi-rational cognition could be located (Hammond 2000). In Figure 1, the one-dimensional cognitive continuum is visualized.

\section{Please Insert Figure 1 About Here}

However, the representation of the cognitive continuum on a single dimension seems to imply that the style is exclusively determined by the relative use of the cognitive processes. The onedimensional scale does not allow for independent variations in the intensity of using the two information systems. It has however been observed that different levels of cognitive activity exist. The alleged existence of variation in the relative use of each system on the one hand and in the 'intensity of use' of each system on the other, leads us to propose a two dimensional conceptualization of the cognitive continuum. This is graphically represented in Figure 2, as a matrix with four quadrants. 
Based upon deduction, and supported by observations of practicing decision-makers (cf. Van Riel and Lievens 2004), we thus propose to distinguish four basic decision styles, reflecting the four quadrants of the cognitive style matrix. We describe the styles in clockwise order, starting with rational analysis:

1. First, a primarily rational style is characterized by the predominant use of the rational information processing system. This style is stepwise, calculative, critical and explicit. It is e.g. externalized in rule-based decision support systems.

2. Second, a style characterized by a mix of relatively effortless analytical thinking and the use of experiential cognition of a limited scope can be observed. Common sense, and also heuristic or routine decision-making are practical examples of this style. It is appropriately characterized by the term 'habit frozen into memory'.

3. Furthermore, a predominantly intuitive style is distinguished, characterized by the almost exclusive and 'intensive' use of the experiential information processing system. This style is inherently uncritical, since the validity of insights is taken for granted.

4. Finally, a combination or integration of effortful rational thinking and the intensive use of experiential cognition characterizes a fourth style. The term active sense making preliminarily refers to this style. The style is simultaneously critical, and creative.

Decision-makers thus seem to have four basic decision styles at their disposition, based on the relative use of two fundamentally different cognitive information-processing systems. Rational analysis and intuition have been discussed extensively, but two considerably different hybrid styles have been identified, that require further clarification: 
- The term 'common sense' is used to refer to what has often been called 'quick and dirty' cognition. Common sense inspired decision-making is characterized by a high degree of efficiency and effectiveness under most common circumstances. It is used in cases of relatively limited complexity and substance, and in cases where little or no in-depth justification is required. The use of heuristics, cognitive shortcuts, and routine are all related forms of common sense inspired decision-making: common sense decisionmakers generally assume a relatively uncritical, uncreative and conformist attitude. Common sense seems to work best in situations that are characterized by a relatively high degree of regularity. Decision-makers use new information very selectively and rely on the validity of previous experience, with relatively little effort. The validity of judgments based on common sense is always indirect and often based upon external authority.

- The term 'active sense making' refers to what takes place when decision-makers combine intense rational analysis with a great openness to intuitive insights. The decision-maker may put much effort into either reconciling his private or subjective intuitive insights with what is objectively known, or indeed into externalizing private knowledge. Therefore it seems that this mode can be genuinely synthetic or creative in nature: It has the potential of producing really new insights, a power that has traditionally - and seemingly erroneously - been attributed to intuition alone (Bowers et al. 1990). It seems, therefore, that only active sense making, precisely in its combination of logical analysis and intuitive insights, is authentically creative (Goldberg 1983; Kuhn 1996; Prietula and Simon 1989), even visionary (Agor 1986). Anecdotal evidence points at the use and suitability of this style under very challenging conditions that require limited justification of separate steps, and much creativity, and where the decision- 
maker is held accountable for the process as a whole rather than for individual decisions or motivations.

\section{The Relationship between Task Characteristics and the Use of Cognitive Systems}

In studies of management decision-making, the relative use of the respective cognitive systems has been posited to reflect the requirements of the task to which a decision-maker is exposed. It has also been proposed that an optimal match exists between requirements and decision style (Payne 1997; Payne et al. 1990; Shapiro and Spence 1997; Spence and Brucks 1997). In order to address the question with respect to the decision-maker's choice or proneness of using different styles under various conditions, a better understanding must be developed of how information is processed in the different styles on the one hand, and what kind of information is processed on the other.

Managers transform information or knowledge into action through their decisions (March 1991). The core cognitive activity involved in the decision-making process is thus productively conceptualized as a 'transformation process' of a 'cognitive input' into a 'cognitive output', which drives subsequent managerial action. First, existing knowledge will be reviewed with respect to the nature of intuitive and rational cognitive transformation processes and of their respective output.

\section{The Rational Transformation Process}

The rational process has been used as a preferred example for most epistemological theories and has thus been studied extensively and described in innumerable places. Hence, we will focus on those aspects that distinguish rational analytical cognition most clearly from intuition. Rational thinking, or reasoning, is generally thought of as an explicit and sequential process that can be controlled and reproduced by the thinker and by any other person 'accepting the rules of logic'. 
The development of rational knowledge is deductive and analytical. The decision-maker follows a series of predetermined and communicable steps that transform given external or internal (Kahneman et al. 1982) information according to these rules of logic. Reasoning is thus seen as the processing of selected cognitive content, using the logic of causality: an intentional, constructive, rule-based and conscious activity. The building blocks of analytical or rational knowledge are pieces of information or judgments. Rational thinking provides the manager with high cognitive control and high awareness, but is typically slow and can require intense structuring efforts from the decision-maker, depending on the complexity of the problem to be solved. Rational decision-making therefore occurs in steps and allows the decision-maker to break up the problem, and if necessary, to distribute the parts over several experts. The effects of emotions, which are typically the result of individual experience, can be filtered out or neutralized in rational thinking, which makes the process more objective. Rational processing can be controlled in terms of its 'intensity'. The decision-maker can determine into how much detail he or she will go.

The utility of rationally obtained knowledge can be increased by reorganizing existing knowledge, the integration of extra (internal or external) information or a combination, and is based upon logical deduction. Rational output again takes the form of judgments or knowledge that can be analyzed into their logical components, and has a high degree of internal validity. The meaning of rational judgment is or can be communicated, shared and justified with the same arguments used to arrive at the output. The decision-maker has control over the degree of detail. Rational output is always partial, necessarily incomplete. External validity of rational output must and can only be obtained through empirical testing. 


\section{The Intuitive Transformation Process}

It has been observed by many decision-makers that intuitive cognition, contrary to rational activity, produces solutions in their entirety and instantaneously (Bowers et al. 1990). A complete solution emerges as it were in the mind of the individual decision-maker. The person experiencing intuition suddenly sees how something could be done (Parikh et al. 1994; Vaughan 1990). It is often reported that intuitive decision-makers have genuine problems articulating their preference of one alternative solution over another (Morris 1967), or how they arrived at that preference (Khatri and Ng 2000; Shapiro and Spence 1997; Simon 1997; Vaughan 1990). They also cannot exert cognitive control over the intuitive process, e.g. by breaking up the decision problem in parts. At the same time, no control appears to be exerted over the 'intensity' or comprehensiveness of the process, although decision-makers can suppress or allow their intuitive insights. The intuitive process occurs non- or subconsciously (Bastick 1982; Rowan 1989), and is provoked rather than actively used. Possibly as a result of this, it appears to be fast and not to require much effort (Bowers et al. 1990; Burke and Miller 1999; Hammond et al. 1987; Shirley and Langan-Fox 1996). When confronted with a problem, individuals often have a feeling almost instantaneously of what the right solution could be. Intuition is therefore often compared to perceptual functions such as 'seeing' or 'recognizing' a truth. Another important observation is that intuitive cognition is inductive (Agor 1984; Westcott 1968), integrating or connecting distributed knowledge, or experience originating from different domains of reality (Kuo 1998) and from different internal or external sensory organs (Weick 1985). It is therefore also called 'behavioral' (McCall Jr. and Kaplan 1990). The intuitive process is contrasted with rational cognition in Table 2.

Please Insert Table 2 About Here 
Most authors stress that output from the intuitive system is self-evident (Epstein 1998; Shirley and Langan-Fox 1996; Vaughan 1990). Intuitive decision-makers simply 'know' the outcome and intuitive cognition inspires great confidence to the person experiencing the intuition (Bowers et al. 1990; Hammond et al. 1987; Shapiro and Spence 1997; Simon 1987). However, intuitive knowledge seems to be the result of a highly individual process, both in terms of inputs and of processing (or associating), and it is therefore difficult to justify and validate intuitive insights publicly, in an objective or even intersubjective sense (Molloy and Schwenk 1995). As a result, it is generally not possible to demonstrate the validity of intuitive knowledge in a similar way as the validity of rational knowledge can be demonstrated. Based upon the characteristics of the intuitive cognitive process a number of possible functions for pure intuitive cognition have been established. These functions are listed in Table 3.

Please Insert Table 3 About Here

\section{Task Related Antecedents of Decision-Maker Preference for a Cognitive Mode}

Characteristics of the decision task and their relationship with the relative use of the two information-processing systems can now be discussed. Hammond et al. (1987) distinguish between task characteristics inducing the use of the analytical system and characteristics inducing the use of the intuitive system, but their one dimensional conceptualization of the cognitive continuum does not allow them to posit independent effects of task characteristics on the relative use of the two systems. The following decision task characteristics, generally not occurring in isolation, have been identified in managerial decision-making literature: the availability of information, problem complexity (Weick 1990), problem structuredness (Mintzberg et al. 1976), the extent to which solving a problem requires the use of practical skills or tacit knowledge from the decision-maker (Wagner 1987; Wagner and Sternberg 1986; Wagner and Sternberg 1987), time pressure and the extent to which a rational justification of 
decisions is required (Van Riel and Lievens 2004). Each of these characteristics will be discussed in the following.

\section{Availability of Information}

First, decision tasks vary in terms of the relative availability of explicit data and information. Since strictly rational decision-making requires accurate and well structured information (Schoemaker 1982), the extent to which rational analysis can lead to effective decision-making will vary with the relative availability and quality of information. Newly acquired information can immediately be integrated with existing explicit knowledge and processing more explicit information will lead to more useful knowledge. Based on previous research we therefore contend that a positive relationship will exist between the amount of relevant information available to decision-makers and the likelihood of making decisions rationally.

P1: There will be a positive relationship between the amount of information available to the decision-maker and the extent to which decision-makers are likely to make use of rational analysis to increase useful knowledge.

It has been argued, that in situations where complete, accurate and timely information is lacking, a shift could occur towards the use of intuitive cognition (Harper 1988). Past experience could work as a substitute for explicit information, arguably the only substitute we have, and thus fill the 'gaps'. Although intuition may be the only source of knowledge in a situation where information is completely lacking, it is not obvious that intuition is necessarily less likely to be used in situations where much information is available. Even in an information rich environment, specific information could still be missing, and intuition could be used to fill these gaps. The likelihood of using intuitive cognition appears to be independent of information availability in general. 


\section{The Role of Tacit Knowledge}

Second, decision tasks differ in terms of the extent to which tacit or implicit knowledge plays a role (Polanyi 1969; Polanyi 1962; Polanyi 1966). For example, in the case of new service development, managers build up a feeling for customer requirements over time. The skill to take customer requirements into account when developing a new service is largely tacit. The effectiveness of decision-making can thus decrease when existing tacit knowledge is ignored. It has been proposed that decision-makers access accumulated tacit, or non-articulate knowledge through their intuition. We thus expect:

P2: There will be a positive relationship between the perceived importance of tacit knowledge to the solution of a decision problem and the extent to which decision-makers are likely to use their intuition to increase knowledge utility.

As a consequence of its nature, tacit knowledge cannot be easily or rapidly articulated and will therefore be largely neglected in rational analysis. We expect that there will not be a relationship between the perceived importance of tacit knowledge to the solution of a decision problem and the extent to which a decision-maker is likely to use rational analysis to increase knowledge utility.

\section{Structuredness of the Task}

Third, decision tasks vary with respect to what is called the structuredness of the decision context (e.g. Mintzberg et al. 1976). Rational analytical processing requires a well-structured decision problem. When the problem appears clearly structured to decision-makers, they can make rational calculations. We thus expect: 
P3: There will be a positive relationship between the perceived structuredness of the decision context and the extent to which a decision-maker is likely to use rational analysis to increase knowledge utility.

In many cases, for example in strategic decision-making, problems are ill structured. Ill structured problems are characterized by a high degree of uncertainty about the actual situation, about the desired situation or about the way to get there, or a combination. Since rational analysis is unsuitable for ill-structured problems, and intuition seems to deal with the context in a more holistic way not requiring a great degree of problem structuredness, we expect:

P4: There will be a negative relationship between the perceived structuredness of the decision problem and the extent to which decision-makers are likely to use their intuition to increase knowledge utility.

\section{Complexity}

Furthermore, task conditions vary with respect to the complexity of the decision context and the problems that are to be dealt with by the manager. Problem complexity could be abstractly described by the number of cues or issues that play a role in a decision problem (Hammond et al. 1987). As a consequence of the physical constitution of our brains, rational decision-makers experience considerable difficulty in dealing with complexity. Great complexity requires great processing effort from the decision-maker, which can be a scarce resource under conditions of time pressure. We therefore expect:

P5: There will be a positive relationship between the perceived complexity of the decision problem and the extent to which a decision-maker is likely to make use of rational analysis to increase knowledge utility. 
Expertise has been characterized as the ability to reduce complexity (Blattberg and Hoch 1990; Simon 1987). The intuitive process, making use of expertise, seems more effective than rational processing in task environments characterized by high levels of complexity. We expect:

P6: There will be a positive relationship between the perceived complexity of the decision problem and the extent to which decision-makers are likely to use their intuition to increase knowledge utility.

\section{Time Pressure}

Time pressure not only hinders the time-intensive rational decision process, but also reduces the amount of high quality information that can be gathered by the decision-maker, we expect:

P7: There will be a negative relationship between perceived time pressure and the extent to which the decision-maker is likely to use rational analysis to increase knowledge utility.

We do not expect there to be a relationship between perceived time pressure and the extent to which decision-makers are likely to use their intuition to increase knowledge utility.

\section{Need for Justification}

Another aspect of the decision situation is the extent to which decision-makers owe a rational justification for individual decisions to superiors (Van Riel and Lievens 2004). Since rational justifications can be produced easily when the decision is made rationally, it is expected that:

P8: There will be a positive relationship between perceived need for justification of individual decisions, and the extent to which the decision-maker is likely to use rational analysis to increase knowledge utility. 
Intuitive decision-making is less effortful and may therefore be more attractive to decisionmakers when there is little need for justification:

P9: There will be a negative relationship between perceived need for justification of individual decisions and the extent to which the decision-maker is likely to use intuition to increase knowledge utility.

\section{Scope of the Cognitive Systems}

Output and transformation of the two information-processing systems have been discussed in the previous paragraphs. In this paragraph differences in scope, and corresponding limitations with respect to the valid use of the two cognitive systems will be inferred from differences in the nature of the respective input.

\section{Factors Moderating the Validity of Rational Analysis}

Which factors moderate the effectiveness of rational processing in creating or increasing the utility of knowledge? In existing literature about bounded rationality in managerial decisionmaking, but also in epistemology, a number of moderators have been identified. The input of any rational or logically based information processing system, be it human or electronic, must consist of articulate arguments with well-defined semantics (Wittgenstein 1953), built on informational components, each reflecting facts or observations (Wittgenstein 1922). The input of the rational system is formal and explicit, and expressed in a more or less symbolic language. The actor of the transformation process is required to select the inputs of the rational process. As a result, the author of the process also has control over, and responsibility for, the selection of (finite) input. Since the human information processing capacity is limited, the decision-maker can and must deliberately include certain information and exclude other (Simon 1997). The decision-maker must also consciously assign weights or values to each fact, reflecting relative 
importance and meaning and is therefore prone to bias (Kahneman et al. 1982). What is actually selected as an input of rational processing is therefore dependent on the extent to which the decision-maker is able to make sense out of the situation (March 1997; Weick 1995). This brings in a dimension of bounded rationality. Values and weights are generally discussed and established in agreement with the dominant logic of the company (Bettis and Prahalad 1995; Grant 1988; Prahalad and Bettis 1986). Summarizing these arguments, we expect:

P10: The extent to which a decision-maker will be able to increase knowledge utility by making use of rational analysis will be moderated by various bounds imposed on the rationality of the decision-maker.

\section{Factors Moderating the Validity of Intuition}

The intuitive process differs substantially from rational analysis with respect to its input. An important characteristic of intuitive cognition is that, whatever the origin of the knowledge, at the moment the intuitive insight occurs to the decision-maker, its input is sourced internally rather than externally. With respect to the origin of this knowledge, intuitive insight is often said to reflect individual expertise (Kuo 1998; Simon 1997) and to be based on individual experiences (Weick 1985). As a result it can be expected that:

P11a: The extent to which a decision-maker will be able to increase knowledge utility by making use of intuitive cognition will be moderated by the presence of valid individual experience or expertise in the mind of the decision-maker.

What can be considered valid experiential knowledge or expertise? Since the intuitive decisionmaker relies on past experience and tacit learning, the experientially acquired knowledge will be as domain-specific or non-specific (Kuo 1998; Simon 1987) and as reliable as the experiences of the individual decision-maker (Isenberg 1984). Therefore: 
P11b: There will be a positive relationship between the extent to which the area of expertise, or the domain within which the decision-maker acquired experience, match the decision-problem, and the validity of experientially gathered knowledge.

An important input of intuition consists of implicit or tacit knowledge, or skills (Polanyi 1969), resulting from extensive experience (Agor 1986; Brockmann and Simmonds 1997; Isenberg 1984; Perkins and Rao 1990; Rowan 1989; Seebo 1993; Simon 1997; Wagner and Sternberg 1987). Tacit knowledge is said to be stored in the form of condensed associative patterns in long-term memory. As a result of the way it is built up and stored in memory, intuition is stable and not easily disrupted. Updating of tacit memory, or the input to the intuitive process, does not seem to occur directly, but rather through repeated experiences of similar, but structurally changing patterns. As a result, the validity of experientially gathered knowledge will be inversely related to the speed of change in the area where the expertise is acquired. If the speed of change is considerable, the experientially gathered knowledge may rapidly become obsolete. Therefore it may be expected that:

P11c: The extent to which a decision-maker will be able to increase knowledge utility by making use of intuitive cognition will be moderated by the amount of turbulence in a decision problem domain.

Some authors stressed that original (and consistent) emotional components of the experience may play an important role in the (re-) production of intuitive knowledge (Bastick 1982; Epstein 1998), since the associative processes underlying intuitive knowledge production are holistic. The repeated experience of any type of pattern-like perception, external or internal, can contribute to the production of intuitive knowledge. Since emotional involvement is generally considered to affect the objectivity of the decision-maker's judgment in a negative sense, we expect: 
P11d: There will be an inverse relationship between the extent to which the decision-maker was emotionally involved while acquiring the experience, and the objective validity of the experientially gathered knowledge.

\section{Construction of a Theoretical Model}

Theorists and practicing decision-makers would probably agree that under most circumstances the use of both the intuitive system and the rational system could contribute to an increase of useful knowledge. Most decision-making therefore occurs as quasi-rational thinking (Hammond and Brehmer 1973). Quasi-rational thinking has been conceptualized as a combination of analytical and intuitive information processing (Shapiro and Spence 1997; Simon 1997). The likelihood of the decision-maker using each of the systems will depend on the task conditions, and the potential contribution to an increase in the utility of knowledge on the presence of moderators influencing the effectiveness of each of the cognitive mechanisms. In Figure 3 the theoretical model, integrating the propositions developed earlier, is summarized.

\section{Please Insert Figure 3 About Here}

\section{Implications for the Scope of Decision Styles}

The identification of limitations to the decision-makers' power to increase the decision-making utility of knowledge by using the cognitive systems under particular task conditions has implications for the scope of the four identified decision styles. Based on the above analysis, it can be concluded that the rational style is probably most effective under conditions where sufficient reliable information can be gathered about all important aspects of a decision problem, whereas the decision problem itself should also be substantially structured. The common-sense style will work under relatively stable and well-known conditions, or conditions that evolve along regular patterns and where decisions are less consequential. The intuitive style 
will lead to effective decision-making under not too quickly or radically changing conditions where the decision-maker has much experience. The active sense making style could be effective where none of the other decision styles may lead to effective decisions: under very turbulent conditions, and as long as the decision-maker is self-critical, knowledgeable and experienced.

\section{Conclusion}

The purpose of this study was to relate decision styles with decision-making effectiveness and to develop coherent theoretical insight into potential benefits and liabilities of the use of different decision styles under various conditions. A thoughtful evaluation and recombination of existing theories in the fields of cognitive psychology and decision-making under uncertainty has provided a number of new insights, and led to the construction of a coherent theoretical model. First, it was proposed to view the two cognitive systems underlying all decision-making as independent and complementary. Thus the Cognitive Continuum Theory was reformulated, leading to a distinction of four fundamental decision styles. The proposed reformulation allows a theoretical distinction between substantially different forms of semi-rational decision-making: Strategic sense making on the one hand and the use of common sense and heuristics on the other. Furthermore, the likelihood of decision-makers using the two underlying cognitive systems was associated with various characteristics of decision tasks. Finally, propositions were formulated with respect to the factors affecting the effectiveness of different styles, based upon differences in the input of the information processing systems. The propositions were integrated in a comprehensive model.

\section{Managerial Implications}

Cautiously, and in anticipation of an empirical confirmation of the proposed model, managerial implications can be formulated in a number of areas. First, it can be argued that decision teams 
at work under difficult conditions should be composed of decision-makers with different preferred styles, compensating for each other's cognitive limitations. Second, based on an analysis of the task conditions, the needs for information and experience should be established. According to the identified needs, resources can subsequently be allocated to the acquisition of required information and expertise, and a suitable decision style can be chosen. Third, again based upon an analysis of the task conditions, the trade off between costs and benefits of rational justification of decisions should be evaluated. Finally, positive and negative effects of imposing or relieving time pressure on decision-makers can be evaluated. It should be noted, that the task conditions occurring during many business processes change dynamically. In some projects, e.g. an innovation project, an evolution will take place from a situation of little time pressure, but extreme ambiguity and uncertainty at the outset, to much lower levels of ambiguity and uncertainty, but very high levels of time pressure towards the end. The further decision-makers proceed in a project, the more information will become available, and problems will become more and more structured, implying that there will be a shift towards using more analysis. At the end of the process, it can be expected that most decisions will be made on a rational basis. It could be expected that especially at the start of an innovation project, expert managers might be more effective decision-makers, as long as they do not ignore informational cues. In view of our conceptual model, the validity of experientially gained knowledge will be highly dependent on the relative stability of the problem area and the efforts and ability of the decision-maker to keep up with changes in their field of expertise or experience. Furthermore, in the case that decision problems are ill structured, complex, inarticulate and accompanied by time pressure and a lack of data (e.g. at the outset of a new product development project), decision-makers could gain increased control by using active sensemaking. 


\section{A Research Agenda}

A range of issues requires further research. In the first place, the conceptual model that was developed should be operationalized. Reliable measurement instruments must be developed, allowing a quantification of the relations between constructs. Second, to confirm the proposed independence of the two cognitive systems, and to obtain insight in the relative effects of various antecedents and moderators on decision-making effectiveness, the model should be empirically validated and refined. Third, research into the information requirements and validity of the hybrid style of active sense making, which seems to play a pervasive role in dynamic and complex business environments, as well as in scientific and medical problem solving, is now of great importance. Fourth, various task characteristics have been identified and studied in many different research streams and research is needed to increase and systematize the existing knowledge. Interaction and/or hierarchical effects should also be investigated. Fifth, the outcome variables need to be carefully operationalized and measured. Finally, contingency approaches to the validity of this model in diverse cultural contexts appear to be of interest. 


\section{References}

Agor, Weston $\mathrm{H}$.

1984 'Using intuition to manage organizations in the future'. Business Horizons, 27/4: 49-54.

Agor, Weston $\mathrm{H}$.

1986 'The logic of intuition: How top executives make important decisions'. Organizational Dynamics, 14/3: 5-9.

Barnard, Chester I.

1938 Functions of the Executive. Cambridge MA: Harvard University Press.

Bastick, Tony

1982 Intuition: How we Think and Act. New York: Wiley.

Bazerman, Max H.

2001 Judgment in Managerial Decision Making (5th ed.). New York: Wiley.

Bechara, Antoine, Hanna Damasio, Daniel Tranel, and Antonio R. Damasio

1997 'Deciding advantageously before knowing the advantageous strategy'. Science, 275: 1293-1295.

Behling, Orlando, and Norman L. Eckel

1991 'Making sense out of intuition'. Academy of Management Executive, 5/1: 46-47.

Bettis, Richard A., and C.K. Prahalad

1995 'The dominant logic: Retrospective and extension'. Strategic Management Journal, 16: 5-14.

Blattberg, Robert C., and Stephen J. Hoch

1990 'Database models and managerial intuition: 50\% model and 50\% managers'. Management Science, 36/8: 887-899.

Bowers, K.S., G. Regehr, C. Balthazard, and L. Baer

1990 'Intuition in the context of discovery'. Cognitive Psychology, 22: 72-110.

Briggs-Myers, Isabel, and Mary H. McCaulley

1985 Manual: A Guide to the Development and Use of the Myers Briggs Type Indicator. Palo Alto, CA: Consulting Psychologists Press.

Brockmann, Erich N., and Paul G. Simmonds

1997 'Strategic decision-making: The influence of CEO experience and use of tacit knowledge'. Journal of Managerial Issues, 9/4: 454-467.

Brunswik, Egon

1952 The Conceptual Framework of Psychology. Chicago, IL: University of Chicago Press.

Burke, Lisa A., and Monica K. Miller

1999 'Taking the mystery out of intuitive decision making'. Academy of Management Executive, 13/4: 91-99. 
Churchland, Paul

1995 The Engine of Reason, the Seat of the Soul: A Philosophical Journey into the Brain. Cambridge MA: The MIT Press.

Denes-Raj, Veronika, and Seymour Epstein

1994 'Conflict between intuitive and rational processing: When people behave against their better judgment'. Journal of Personality and Social Psychology, 66/5: 819-829.

Dutta, Soumitra

1993 Knowledge Processing and Applied Artificial Intelligence. London: ButterworthHeinemann.

Eisenhardt, Kathleen M., and Behnam N. Tabrizi

1995 'Accelerating adaptive processes: Product innovation in the global computer industry'. Administrative Science Quarterly, 40/1: 84-110.

Epstein, Seymour

1994 'Integration of the cognitive and the psychodynamic unconscious'. American Psychologist, 49: 709-724.

Epstein, Seymour

1998 'Cognitive-experiential self theory: A dual process personality theory with implications for diagnosis and psychotherapy' in Empirical Perspectives on the Psychoanalytic Unconscious, R.F. Bornstein and J.M. Masling (eds.): 99-140. Vol. 7. Washington: American Psychological Association.

Epstein, Seymour, S. Lipson, C. Holstein, and E. Huh

1992 'Irrational reactions to negative outcomes: Evidence for two conceptual systems'. Journal of Personality and Social Psychology, 38: 889-906.

Galbraith, Jay R.

1973 Designing Complex Organizations. Reading MA: Addison-Wesley.

Galbraith, Jay R.

1974 'Organization design: An information processing view' in Organizational Psychology, D.A. Kolb (ed.) 313-322. 2nd ed. Englewood Cliffs, NJ: Prentice Hall.

Goldberg, Philip

1983 The Intuitive Edge. New York: Putnam.

Goldberg, Philip

1990 'The many faces of intuition' in Intuition in Organizations, W.H. Agor (ed.) 62-77. Newbury Park, CA: Sage Publications.

Grant, Robert M.

1988 'Research notes and communications on 'dominant logic', relatedness and the link between diversity and performance'. Strategic Management Journal, 9: 639-642.

Hammond, Kenneth R. 
1996 Human Judgment and Social Policy: Irreducible Uncertainty, Inevitable Error, Unavoidable Injustice. New York: Oxford University Press.

Hammond, Kenneth R.

2000 'Coherence and Correspondence Theories in Judgment and Decision Making' in Judgment and Decision Making: An Interdisciplinary Reader, T. Connolly, H.R. Arkes and K.R. Hammond (eds.): 53-65. 2nd ed. New York: Oxford University Press.

Hammond, Kenneth R., and Berndt Brehmer

1973 'Quasi-rationality and distrust: Implications for international conflict' in Human Judgment and Social Interaction, L. Rappoport and D.A. Summers (eds.). New York: Holt, Rinehart and Winston.

Hammond, Kenneth R., Robert M. Hamm, Janet Grassia, and Tamra Pearson

1987 'Direct comparison of the efficacy of intuitive and analytical cognition in expert judgment'. IEEE Transactions on Systems, Man and Cybernetics, SMC-17/5: 753-770.

Harper, Stephen C.

1988 'Intuition: What separates executives from managers'. Business Horizons, 31/5: 13-19.

Isaack, Thomas S.

1978 'Intuition: An ignored dimension of management'. Academy of Management Review, 3/October: 917-922.

Isenberg, Daniel J.

1984 'How senior managers think'. Harvard Business Review, 62/6: 81-90.

Jung, Carl Gustav

1971 Psychological Types. Princeton, NJ: Princeton University Press.

Kahneman, Daniel, Paul Slovic, and Amos Tversky eds.

1982 Judgment under Uncertainty: Heuristics and Biases. Cambridge: Cambridge University Press.

Khatri, Naresh, and H. Alvin Ng

2000 'The role of intuition in strategic management'. Human Relations, 53/1: 57-86.

Kuhn, Thomas

1996 The Structure of Scientific Revolutions (3rd ed.). Chicago, IL: University of Chicago Press.

Kuo, Feng-Yang

1998 'Managerial intuition and the development of executive support systems'. Decision Support Systems, 24/2: 89-103.

March, James G.

1991 'Exploration and exploitation in organization learning'. Organization Science, 2: 71-87.

March, James G. 
1997 'Understanding how decisions happen in organizations' in Organizational Decision Making, Z. Shapira (ed.) 9-32. Cambridge: Cambridge University Press.

March, James G.

1999 The Pursuit of Organizational Intelligence. Maiden MA: Blackwell Scientific Publishers.

McCall Jr., Morgan W., and Robert E. Kaplan

1990 Whatever It Takes: The Realities of Managerial Decision Making (2nd ed.). Upper Saddle River, NJ: Prentice-Hall.

Meehl, Paul E.

1996 Clinical versus Statistical Prediction: A Theoretical Analysis and a Review of the Evidence. Minneapolis, MN: University of Minnesota Press.

Mintzberg, Henry, Duru Raisinghani, and André Théorêt

1976 'The structure of 'unstructured' decision processes'. Administrative Science Quarterly, 21/2: 246-275.

Molloy, Steve, and Charles R. Schwenk

1995 'The effects of information technology on strategic decision making'. Journal of Management Studies, 32/3: 283-311.

Morris, William T.

1967 'Intuition and relevance'. Management Science, 14/4: 157-165.

Myers, David G.

2002 Intuition - its powers and perils. New Haven: Yale University Press.

Parikh, J., F.F. Neubauer, and A.G. Lank

1994 Intuition, the New Frontier of Management. Oxford: Blackwell.

Payne, John W.

1976 'Task complexity and contingent processing in decision making: An information search and protocol analysis'. Organizational Behavior and Human Performance, 16: 366-387.

Payne, John W.

1982 'Contingent decision behavior'. Psychological Bulletin, 92: 382-402.

Payne, John W.

1997 'The scarecrow's search: A cognitive psychologist's perspective on organizational decision making' in Organizational Decision Making, Z. Shapira (ed.) 353-374.

Cambridge: Cambridge University Press.

Payne, John W., James R. Bettman, and Eric J. Johnson

1990 The Adaptive Decision Maker: Effort and Accuracy in Choice. Chicago, IL: University of Chicago Press.

Payne, John W., James R. Bettman, and Eric J. Johnson 
1988 'Adaptive strategy selection in decision making'. Journal of Experimental Psychology: Learning, Memory and Cognition, 14/3: 534-552.

Penrose, Edith

1995 The Theory of the Growth of the Firm (revised ed.). New York: Oxford University Press.

Perkins, W. Steven, and Ram C. Rao

1990 'The role of experience in information use and decision making by marketing managers'. Journal of Marketing Research, 27/February: 1-10.

Polanyi, Michael

1962 Personal Knowledge: Towards a Post-Critical Philosophy. New York: Harper Torchbooks.

Polanyi, Michael

1966 The Tacit Dimension. Garden City, NY: Doubleday Anchor.

Polanyi, Michael

1969 'The logic of tacit inference' in Knowing and Being, M. Grene (ed.) 138-157. London: Routledge and Kegan Paul.

Prahalad, C.K., and Richard A. Bettis

1986 'The 'dominant logic': A new linkage between diversity and performance'. Strategic Management Journal, 7/6: 485-501.

Prietula, Michael J., and Herbert A. Simon

1989 'The experts in your midst'. Harvard Business Review, January-February: 120-124.

Rowan, Roy

1989 'What it is' in Intuition in Organizations: Leading and Managing Productively, W.H. Agor (ed.) 121-134. Newbury Park, CA: Sage.

Sauter, Vicky L.

1999 'Intuitive decision-making'. Association for Computing Machinery. Communications of the ACM, 42/6: 109-115.

Schoemaker, P.J.H.

1982 'The expected utility model: Its variants, purposes, evidence and limitations'. Journal of Economic Literature, 20: 529-563.

Seebo, T.C., II

1993 'The value of experience and intuition'. Financial Management, 22/1: 27.

Shanteau, James

1992 'Competence in experts: The role of task characteristics'. Organizational Behavior and Human Decision Processes, 53: 252-266.

Shapiro, Stewart, and Mark Spence 
1997 'Managerial intuition: A conceptual and operational framework'. Business Horizons, 40/1: 63-69.

Shirley, Debbie A., and Janice Langan-Fox

1996 'Intuition: A review of the literature'. Psychological Reports, 79: 563-584.

Simon, Herbert A.

1957 Models of Man: Social and Rational - Mathematical Essays on Rational Human Behavior in a Social Setting. New York: Wiley.

Simon, Herbert A.

1987 'Making management decisions: The role of intuition and emotion'. Academy of Management Executive, February: 57-64.

Simon, Herbert A.

1997 Administrative Behavior, a Study of Decision Making Processes in Administrative Organizations (4th ed.). New York: Free Press.

Spence, Mark T., and Merrie Brucks

1997 'The moderating effects of problem characteristics on experts' and novices' judgments'. Journal of Marketing Research, 34/May: 233-247.

Taggart, William M., and Dan Robey

1981 'Minds and managers: On the dual nature of human information processing and management'. Academy of Management Review, 6/2: 187-195.

Teglasi, Hedwig, and Seymour Epstein

1998 'Temperament and personality theory: The perspective of cognitive-experiential selftheory'. School Psychology Review, 27/4: 534-550.

Van Riel, Allard C.R., and Annouk Lievens

2004 'High tech service innovation: A decision making perspective'. International Journal of Service Industry Management, 15/1.

Vaughan, Frances E.

1990 'Varieties of intuitive experience' in Intuition in Organizations, W.H. Agor (ed.) 40-61. Newbury Park CA: Sage.

Wagner, Richard K.

1987 'Tacit knowledge in everyday intelligent behavior'. Journal of Personality and Social Psychology, 52/6: 1236-1247.

Wagner, Richard K., and Robert J. Sternberg

1986 'Tacit knowledge and intelligence in the everyday world' in Practical Intelligence: Nature and Origins of Competence in the Everyday World, R.J. Sternberg and R.K. Wagner (eds.): 51-83. New York: Cambridge University Press.

Wagner, Richard K., and Robert J. Sternberg

1987 'Tacit knowledge in managerial success'. Journal of Business and Psychology, 1/4: 301312. 
Weick, Karl E.

1979 The Social Psychology of Organizing (2 ed.). New York: McGraw-Hill.

Weick, Karl E.

1985 'Cosmos vs. chaos: Sense and nonsense in electronic contexts' in Making Sense of the Organization, K.E. Weick (ed.) 444-457. Oxford, UK: Blackwell Publishers.

Weick, Karl E.

1990 'Technology as equivoque: Sensemaking in new technologies' in Making Sense of the Organization, K.E. Weick (ed.) 148-175. Oxford: Blackwell Publishers Ltd.

Weick, Karl E.

1995 Sensemaking in Organizations. Thousand Oaks CA: Sage.

Weick, Karl E.

2001 Making Sense of the Organization. Oxford, UK: Blackwell Ltd.

Westcott, M.R.

1968 Towards a Contemporary Psychology of Intuition. New York: Holt, Rinehart and Winston.

Wittgenstein, Ludwig

1922 Tractatus Logico-Philosophicus. London, UK: Routledge and Kegan Paul.

Wittgenstein, Ludwig

1953 Philosophical Investigations / Philosophische Untersuchungen. Oxford, UK: Blackwell. 
Figure 1: The Cognitive Continuum. Adapted from: Shanteau (1992)

\author{
Intuition Rational Analysis

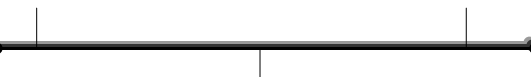 \\ Semi-Rational Cognition
}


Figure 2: The Cognitive Style Matrix

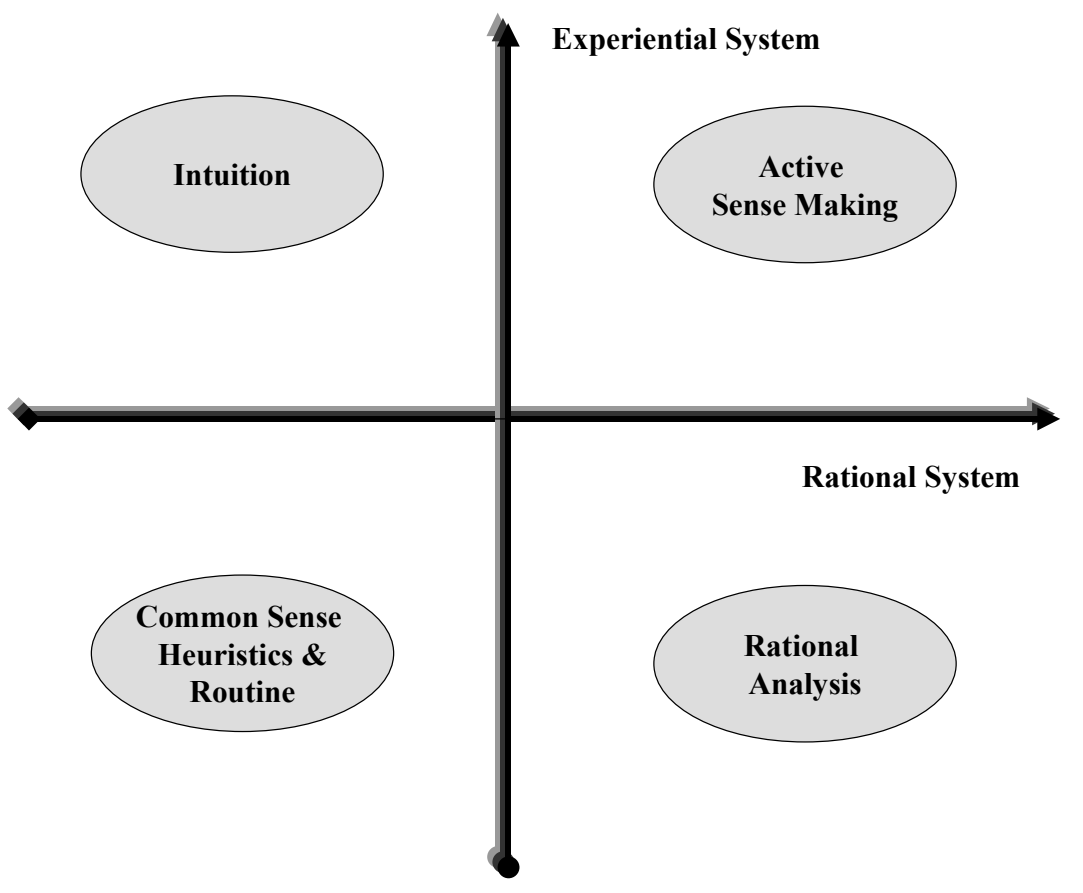


Figure 3: Conceptual Model

Task Characteristics

Moderators

Outcome

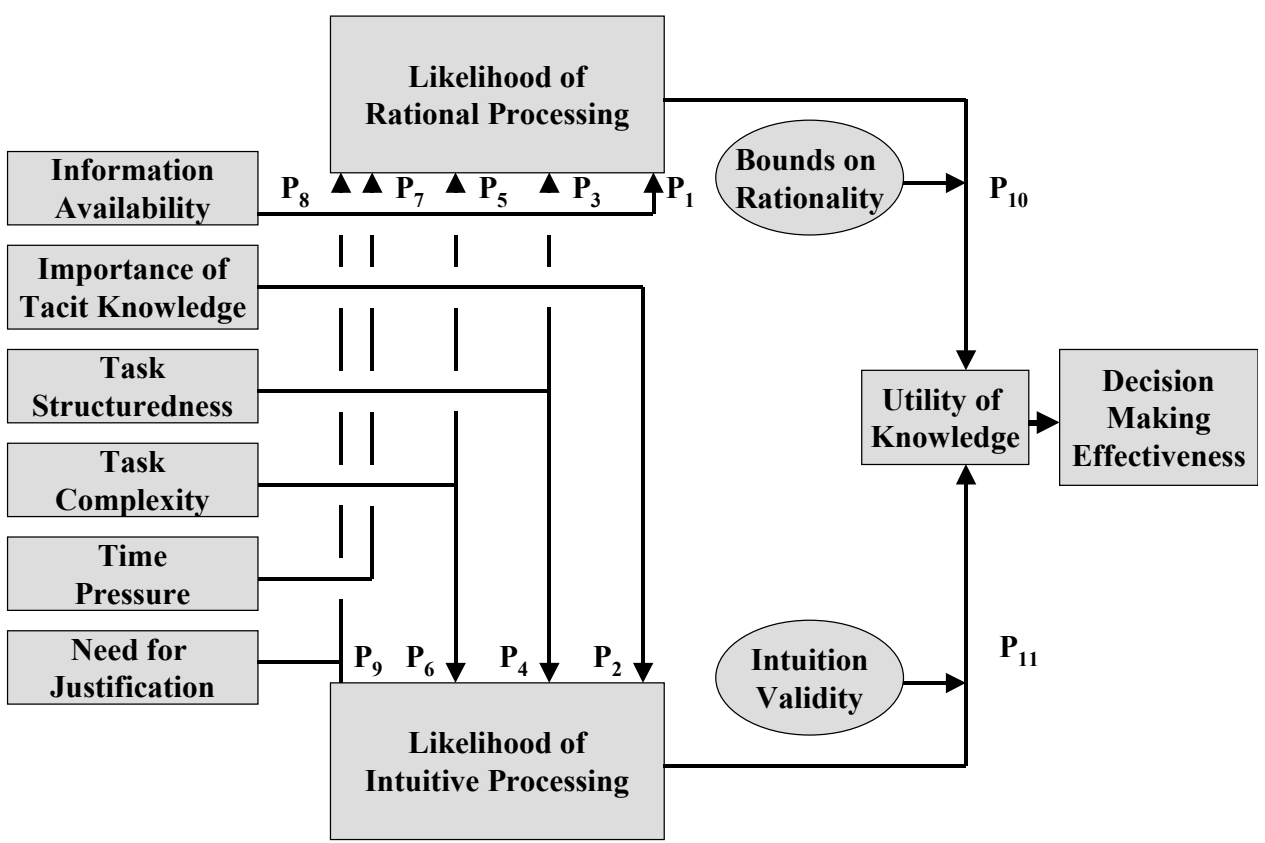


Table 1: Two Cognitive Systems. Adapted from: Teglasi and Epstein (1998)

\begin{tabular}{|c|c|c|}
\hline Feature & Experiential System & Rational System \\
\hline Perspective & Holistic & Analytic \\
\hline Control & Automatic, effortless & Intentional, effortful \\
\hline Orientation & Affective: pleasure-pain oriented (what feels good) & Logical: reason oriented (what is sensible) \\
\hline $\begin{array}{l}\text { Structure of } \\
\text { knowledge }\end{array}$ & Associationist connections & Logical connections \\
\hline $\begin{array}{l}\text { Effect on } \\
\text { behavior }\end{array}$ & Behavior mediated by "vibes" from past events & $\begin{array}{l}\text { Behavior mediated by conscious appraisal } \\
\text { of events }\end{array}$ \\
\hline Form & $\begin{array}{l}\text { Encodes reality in concrete images, metaphors and } \\
\text { narratives: subjective }\end{array}$ & $\begin{array}{l}\text { Objective representation of reality in } \\
\text { abstract symbols: words and numbers }\end{array}$ \\
\hline Productivity & $\begin{array}{l}\text { More rapid processing: oriented toward immediate } \\
\text { action }\end{array}$ & $\begin{array}{l}\text { Slower processing: oriented toward } \\
\text { delayed action }\end{array}$ \\
\hline Adaptivity & $\begin{array}{l}\text { Slower and more resistant to change: changes with } \\
\text { repetitive / intense experience }\end{array}$ & $\begin{array}{l}\text { Changes more rapidly and easily: changes } \\
\text { with strength of argument }\end{array}$ \\
\hline Detail & $\begin{array}{l}\text { More crudely differentiated: broad generalization } \\
\text { gradient, stereotypical thinking }\end{array}$ & More highly differentiated \\
\hline $\begin{array}{l}\text { Coherence of } \\
\text { output }\end{array}$ & $\begin{array}{l}\text { More crudely integrated: dissociative, emotional } \\
\text { complexes, context-specific processing }\end{array}$ & $\begin{array}{l}\text { More highly integrated: context-general } \\
\text { principles }\end{array}$ \\
\hline Control & $\begin{array}{l}\text { Experienced passively and preconscious: we are } \\
\text { seized by emotion }\end{array}$ & $\begin{array}{l}\text { Experienced actively and consciously: we } \\
\text { are in control of our thoughts }\end{array}$ \\
\hline Validity & Self-evidently valid: "experiencing is believing" & $\begin{array}{l}\text { Requires justification via logic and } \\
\text { empirical evidence }\end{array}$ \\
\hline
\end{tabular}


Table 2: Contrasting Rational and Intuitive Processes. Source: Hammond et al. (1987)

\begin{tabular}{lll}
\hline & Intuition & Analysis \\
\hline Cognitive control & Low & High \\
Rate of data processing & Rapid & Slow \\
Conscious awareness & Low & High \\
Organizing principle & Weighted average & Task specific \\
Errors & Normally distributed & Few, but large \\
Confidence in answer & High & Low \\
Confidence in method & Low & High \\
\hline
\end{tabular}


Table 3: Functions of Intuition. Adapted from Goldberg (1983; 1990)

\begin{tabular}{lll}
\hline $\begin{array}{l}\text { Functions of } \\
\text { Intuition }\end{array}$ & Explanation & Key Feature \\
\hline Intuitive discovery & $\begin{array}{l}\text { Goes beyond simply providing answer to certain problem } \\
\text { but is an insight into the real nature of the dilemma. It is }\end{array}$ & Inductivity \\
& $\begin{array}{l}\text { likely to suddenly occur when the mind is actually } \\
\text { occupied with something other than the problem to which } \\
\text { the intuition is related. }\end{array}$ & \\
& $\begin{array}{l}\text { Generates new ideas and involves alternatives and } \\
\text { possibilities rather than facts and provable information. }\end{array}$ & Creativity, non-linearity \\
Creative intuition & $\begin{array}{l}\text { Leads to a feeling to prefer one alternative over the other } \\
\text { antuitive evaluation leads to a feeling of certitude that tentative conclusions }\end{array}$ & \\
& $\begin{array}{l}\text { are correct. } \\
\text { Onfluences and prompts individuals' actions without }\end{array}$ & Tacit Knowledge, experience \\
& $\begin{array}{l}\text { entering consciousness and gives a particular direction of } \\
\text { action that is unexplainable. }\end{array}$ & \\
Deals with the unknown, under which circumstances \\
Intuitive prediction & Synthesis, tacitness \\
Intuitive illumination analysis is ineffective. & $\begin{array}{l}\text { Transcends the other five functions of intuition and is } \\
\text { associated with a higher form of knowing and resembles } \\
\text { the more spiritual side of intuition. }\end{array}$ & Holistic input \\
\hline
\end{tabular}

\footnotetext{
${ }^{i}$ About (the fact that) that all knowledge starts from perceptions (experience), no doubt exists.

${ }^{\text {ii }}$ Obviously, later philosophers, e.g. Kant and Wittgenstein, have critically delimited the possibilities of rational knowledge.
} 